\section{Neurological Syndrome Following Bilateral Damage to the Head of the Caudate Nuclei}

Eric K. Richfield, MD, Roy Twyman, MD, and Stanley Berent, $\mathrm{PhD}$

We describe a persistent behavioral disorder associated with bilateral destruction of the head of the caudate nuclei. The findings in this case support a role for the caudate nuclei in behavioral functions and are interpreted in view of recent anatomical and physiological information on the connections of the caudate nuclei with the prefrontal cortex.

Richfield EK, Twyman R, Berent S: Neurological syndrome following bilateral damage to the head of the caudate nuclei. Ann Neurol 22:768-771, 1987

The basal ganglia are known to be involved in motor functions based on anatomical, physiological, and pathological evidence [1-3]. However, dysfunction of the basal ganglia has also produced changes in a variety of behavioral and cognitive functions in humans and animals including learning, language, personality, and social behavior $\{4-12\}$. The role of the basal ganglia in cognitive functions and social behavior in humans is not well understood and is therefore more speculative. There are several reasons for this. It is difficult to interpret and transfer conclusions about animal data to humans. Animal studies do not allow testing of many human cognitive functions such as language or mathematical ability. Selective basal ganglia damage without conflicting or more extensive pathological involvement in humans is rare. Because animal studies have shown that bilateral lesions are required to produce cognitive abnormalities [12], unilateral human lesions may fail to demonstrate any dysfunction. Finally, because cortical connections to the basal ganglia are widespread [13], the cognitive and behavioral disturbances seen with basal ganglia dysfunction are likely to be complex and difficult to diagnose and classify. We report the behavioral and cognitive changes associated with the clinical occurrence of bilateral selective damage to the head of the caudate nuclei.

From the Department of Neurology, University of Michigan, Ann Arbor, MI.

Received Mar 10, 1987, and in revised form Apr 20 and May 27. Accepted for publication June 7, 1987.

Address correspondence to Dr Richfield, Department of Neurology, University of Michigan, 1103 East Huron St, Ann Arbor, MI 48104 .

\section{Case Report}

The patient was a 25-year-old right-handed woman. Prior to the onset of her illness she had been a high school honor student, was employed full-time, had been living independently, and was engaged to be married. From February to March of 1983 she suffered from daily headaches with occasional nausea and vomiting. In April she disappeared for $A$ days. When found, she had undergone a dramatic personality change manifested by alterations in affect, motivation, cognition, and self-care. She was hospitalized for medical tests including computed tomographic (CT) scan of the head and cerebral angiography. The initial contrast CT revealed enhancement in the head of the caudate nuclei bilaterally without other abnormality (Fig A). Cerebral angiography gave normal results. Therapy with phenytoin and carbamazepine was without benefit. She was unable to work or care for herself and displayed behavior inappropriate to her premorbid state. Her abnormal behaviors included vulgarity, impulsiveness, easy frustration, violent outbursts, hypersomnia, enuresis, indifference, wandering, increased appetite, polydipsia, hypersexuality, minor criminal behavior including shoplifting and exposing herself, and poor hygiene.

On physical examination at the University of Michigan 8 months later, she was inattentive and uninterested in her surroundings or the examiner but could be encouraged to concentrate for short periods of time. She would frequently lie down to sleep but was easily aroused. Her affect was flat. General physical examination was normal. Mental status testing included normal language, full orientation, digit span of seven numbers forward and four numbers backward. Memory testing during neurological examination revealed normal new learning at 5 and 15 minutes and intact recent and remote memory, except for details of her disappearance 8 months before. Similarities and differences were performed normally. She performed simple calculations adequately but was unable to do complex calculations. There was no rightleft disorientation. Her fund of knowledge was impaired for her level of education and premorbid status. The remainder of her neurological examination was normal.

Repeat contrast CT revealed bilateral hypodense areas in the region of the head of the caudate nuclei without other abnormality (Fig B). Other normal tests included electroencephalogram (EEG), evoked potentials, cerebrospinal fluid examination, serum chemistries, and tests for autoimmunity.

Formal neuropsychological testing was performed during her University of Michigan hospitalization and 1 year later (Table). The presence of cognitive impairment, especially in delayed recall on the Wechsler Memory Scale, together with the patient's historical productivity and measured achievement levels (Wide Range Achievement Test) suggest that the low average IQ revealed in the Table represents a decline from premorbid level of intellect. This conclusion is strengthened by the improvement evidenced in subsequent examination 1 year later. Improved performance was especially noted on tasks of new learning and recall but was also evident on the categories subtest of the Halstead Battery, a task of complex problem solving. Formal language testing, administered by a speech pathologist, demonstrated no disturbance in language, except for impairment in comprehension of complex ideational material.

One year after her evaluation at the University of Michi- 

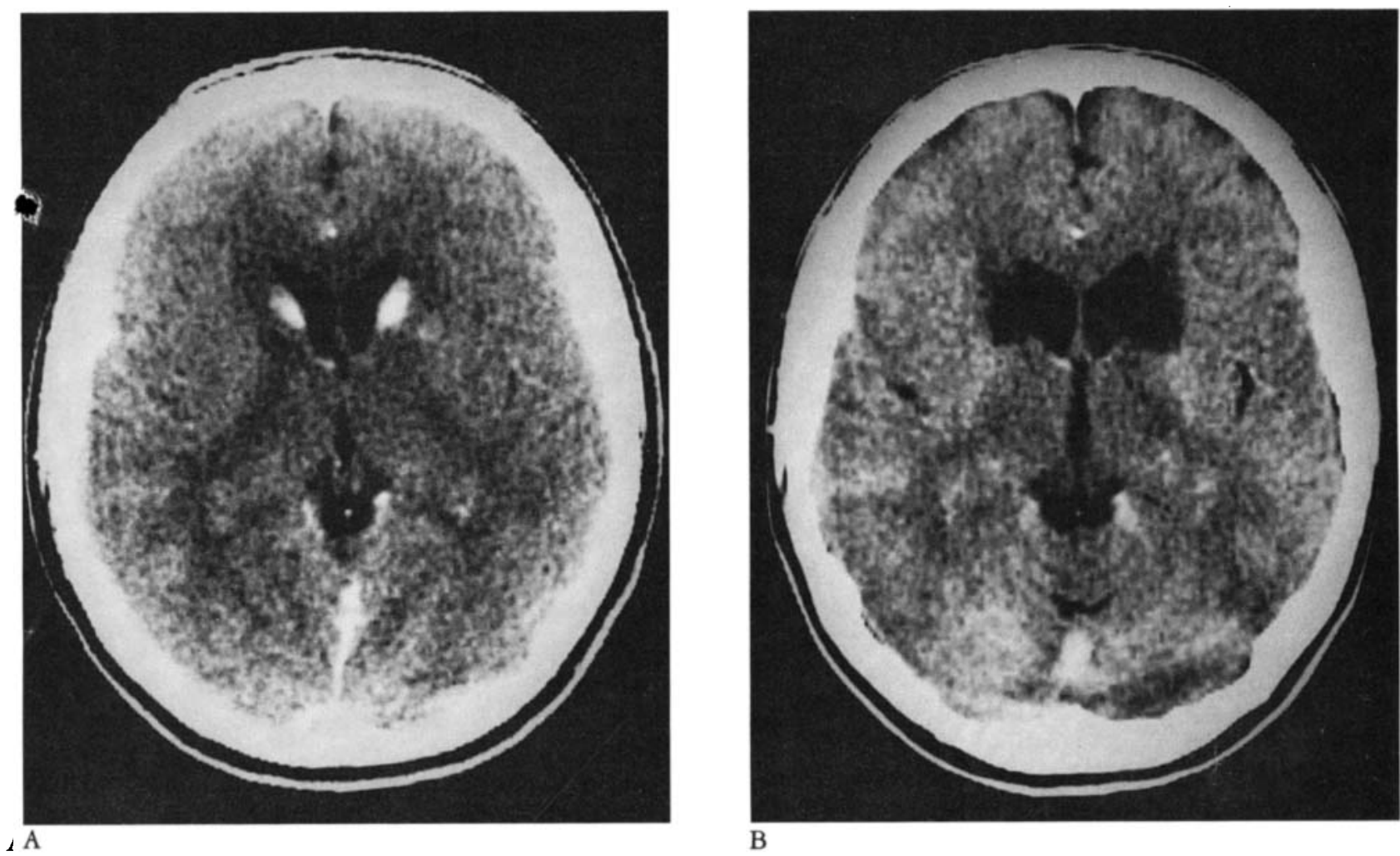

$\triangle A$

Contrast computed tomographic (CT) images through the bead of the caudate nuclei. (A) Contrast CT was performed during the patient's first bospitalization at the onset of ber bebavioral changes. Areas of contrast enbancement can be seen in the head of the caudate nuclei bilaterally. Patbological contrast enhancement was not seen elsewbere in the brain. (B) Contrast CT was performed during the patient's University of Michigan hospitalization 8 months later. Areas of abnormal low density can be seen in the region of the caudate nuclei bilaterally. No other pathological low densities were seen. (CT scans were performed on different $C T$ scanners at sligbtly different orientations.)

gan, the patient had married and divorced, continued to be unemployed, and had little improvement in behavior. Two psychiatric hospitalizations and treatment with a variety of major tranquilizers were not beneficial. There were some improvements in neuropsychological testing after one year (see Table). The basis for the lesions seen on CT scan remains unknown.

\section{Discussion}

Knowledge of function of the caudate nuclei in humans is based on interpretation of clinical cases. Degenerative disorders such as Huntington's disease, Parkinson's disease, or Wilson's disease involve structures in the basal ganglia and other regions of the brain [2]. All three produce motor impairment and may produce behavioral and cognitive changes [2]. For these reasons it is difficult to assign a specific functional role for the caudate nuclei in humans based on these clinical disorders alone. The present case is unique in that

there is bilateral damage restricted to the head of the caudate nuclei in a young person without evidence of other neurological or psychiatric disease. Bifrontal cortical lesions not detected by two contrast CT scans and EEG remain a possibility.

The head of the caudate is known to be part of several neuronal circuits connecting different regions of the frontal lobe with the thalamus and cerebral cortex [3]. Two such circuits have been described, the "dorsolateral prefrontal" and "lateral orbitofrontal," in which the head of the caudate is a major nucleus in the circuit [13]. Prefrontal cortical layers 2 through 6 all send projections to the caudate nuclei bilaterally [14, 15]. The projections from both supragranular and infragranular cortical layers to the caudate nuclei appear to be unique among all other known corticofugal pathways to subcortical structures, which normally arise only from infragranular layers. Because intrahemispheric and interhemispheric connections have been shown to occur normally from both supragranular and infragranular layers in the cat and monkey, the caudate nuclei may work functionally like an analog of the cerebral cortex.

An association between the prefrontal cortex and the caudate nuclei has long been recognized by behavioral neuroscientists. Specific behavioral and learning deficits can be produced by lesions in discrete areas of the prefrontal cortex [16]. These deficits can be repro- 
Results of Formal Neuropsychological Examination ${ }^{\mathrm{a}}$

\begin{tabular}{|c|c|c|}
\hline Test & $\begin{array}{l}\text { Initial } \\
\text { Examination }^{\text {b }}\end{array}$ & $\begin{array}{l}\text { Subsequent } \\
\text { Examination }^{c}\end{array}$ \\
\hline \multicolumn{3}{|l|}{$\begin{array}{l}\text { Wechsler Adult Intelli- } \\
\text { gence Scale-Revised } \\
\text { (W AIS-R) }\end{array}$} \\
\hline Verbal IQ & 84 & \\
\hline Performance IQ & 88 & \\
\hline Full-Scale IQ & 84 & 85 (estimated) \\
\hline \multicolumn{3}{|l|}{ Subtests: } \\
\hline Vocabulary & 7 & 7 \\
\hline Comprehension & 6 & 7 \\
\hline Digit symbol & 7 & 6 \\
\hline Block design & 9 & 10 \\
\hline \multicolumn{3}{|l|}{ Wechsler Memory Scale } \\
\hline MQ & 91 & 96 \\
\hline \multicolumn{3}{|l|}{ Subtests: } \\
\hline I & 6 & 5 \\
\hline II & 5 & 5 \\
\hline III & 7 & 6 \\
\hline IV & 6 & 7.5 \\
\hline V & 11.5 & 9 \\
\hline VI & 11 & 12.5 \\
\hline VII & 11.5 & 6 \\
\hline \multicolumn{3}{|l|}{ Delayed recall: } \\
\hline IV & 0 & 4.5 \\
\hline VI & 8 & 9.5 \\
\hline Rod and frame & 2.6 degrees & 2.9 degrees \\
\hline Dominant hand grip & $26 \mathrm{~kg}$ & $35 \mathrm{~kg}$ \\
\hline Nondominant hand grip & $24 \mathrm{~kg}$ & $28 \mathrm{~kg}$ \\
\hline Halstead categories & 61 & 46 \\
\hline
\end{tabular}

${ }^{2}$ Neuropsychological tests were administered in a standard fashion as part of a battery of tests routinely performed at the University of Michigan.

${ }^{6}$ The initial examination occurred at the University of Michigan 8 months after the onset of her illness.

'Subsequent neuropsychological testing was performed 1 year later using identical testing procedures.

duced in animals following lesions to certain regions of the caudate nuclei $[8,12,17,19]$. Because different areas of prefrontal cortex project to different sectors of the caudate nucleus [18], the deficits following lesions to these areas should be similar. Double dissociation lesion studies have verified the topographical anatomical and behavioral connections in monkey [19]. The behavioral deficits mentioned usually require bilateral lesions to be seen $[12,17]$.

This patient also failed to demonstrate any motor abnormalities that might be expected following damage to a portion of the basal ganglia [1]. Animals with bilateral lesions to the caudate nuclei also fail to demonstrate permanent motor abnormalities [7, 12]. Recent positron emission tomography scan data correlating basal ganglia metabolism with clinical features in patients with Huntington's disease found that the caudate is less involved in motor abnormalities than is the putamen [21]. Young and co-workers also found that a reduced caudate metabolism correlated with total func- tional capacity - a measure of ability to work, handle finances, self-care, and other measures of independence [21]. Our patient showed similar deficits.

The caudate nuclei are a part of the basal ganglia that traditionally have been thought of as having primarily motor functions [1]. Recent animal and clinical studies suggest, however, that the caudate nuclei are critict for "cognitive" functions. Analysis of this patient's deficits supports the notion that portions of the caudate nuclei are involved in processing information related to the prefrontal cortex and behavior. These deficits may be due to a corticocortical disconnection through the caudate nuclei. This disconnection may be responsible for some of the cognitive deficits seen in the "subcortical dementias" including Huntington's disease $[22,23]$.

This work was supported in part by the Tourette Syndrome Association (Bayside, NY).

The authors would like to thank Drs Anne Young and Terry Robinson for helpful comments, Karen Kluin for administering the Boston Diagnostic Aphasic Examination, Shirley Lehtinen for help with neuropsychological testing, and Genell Fries for secretarial assistance.

\section{References}

1. Marsden CD. The mysterious motor function of the basal ganglia: the Robert Wartenberg lecture. Neurology 1982;32:514539

2. Adams RD, Victor M. Principles of neurology. New York: McGraw-Hill, 1986

3. Evered D, O'Connor M, eds. Function of the basal ganglia. Ciba Foundation Symposium 107. London: Pitman, 1984

4. Scheider JS, Lidsky TI. Processing of somatosensory information in striatum in behaving cats. J Neurophysiol 1981;45:841851

5. Damasio AR. Language and the basal ganglia. Trends Neurosci $1983 ; 6: 442-444$

6. Mettler FA, Mettler CC. The effects of striatal injury. Brain 1942;65:242-255

7. Villablanca JR, Marcus RJ, Olmstead CE. Effects of caudate nuclei or frontal cortical ablations in rats. I. Neurology and gross behavior. Exp Neurol 1976;52:389-420

8. Kolb B. Studies on the caudate-putamen and the dorsomedial thalamic nucleus of the rat: implications for mammalian frontallobe functions. Physiol Behav 1977;18:237-244

9. Mettler FA. Effects of bilateral simultaneous subcortical lesions in the primate. J Neuropathol Exp Neurol 1945;4:99-122

10. Francis AF. Familial basal ganglia calcification and schizophreniform psychosis. Br J Psychiatry 1979;360-362

11. Cummings JL, Gosenfeld LF, Houlihan JP, McCaffrey T. Neuropsychiatric disturbances associated with idiopathic calcification of the basal ganglia. Biol Psychol 1983;18:591--601

12. Iverson SD. Behaviour after neostriatal lesions in animals. In: Divac I, Oberg RGE, eds. The neostriatum. New York: Pergamon, 1979

13. Alexander GE, DeLong MR, Strick PC. Parallel organization of functionally segregated circuits linking basal ganglia and cortex. Annu Rev Neurosci 1986;9:359-381

14. Arikuni T, Kubota K. The organization of prefrontal caudate projections and their laminar origin in the macaque monkey: a 
retrograde study using HRP-gel. J Comp Neurol 1986;244 492-510

15. Royce GJ. Laminar origin of cortical neurons which project upon the caudate nucleus: a horseradish peroxidase investigation in the cat. J Comp Neurol 1982;205:8-29

16. Goldman PS, Rosvold HE, Vest B, Galkin TW. Analysis of the delayed alternation deficit produced by dorsolateral prefrontal lesions in the Rhesus monkey. J Comp Physiol Psychol 1971; 2:212-220

17. Villablanca JR, Olmstead CE. The striatum: a fine tuner of the brain. Acta Neurobiol Exp 1982;42:227-299

18. Selemon LD, Goldman-Rakic PS. Longitudinal topography and interdigitation of corticostriatal projections in the Rhesus monkey. J Neurosci 1985;5:776-794

19. Divac I, Rosvold HE, Szwarcbart MK. Behavioral effects of selective ablation of the caudate nucleus. J Comp Physiol Psychol 1967;63:184-190

20. Mesulam MM. Frontal cortex and behavior. Ann Neurol 1986;19:320-324

21. Young AB, Penney JB, Starosta-Rubenstein S, et al. PET scan investigations of Huntington's disease: cerebral metabolic correlates of neurological features and functional decline. Ann Neurol 1986;20:296-303

22. Huber SJ, Shuttleworth EC, Paulson GW, et al. Cortical vs subcortical dementia: neuropsychological differences. Arch Neurol 1986;43:392-394

23. Whitehouse PJ. The concept of subcortical and cortical dementia: another look. Ann Neurol 1986;19:1-6

\section{Transient Global Amnesia: The Electroencephalogram at Onset}

Andrew J. Cole, MD, Pierre Gloor, MD, PhD, and Reed Kaplan, MD

A middle-aged man experienced onset of transient global amnesia while undergoing an electroencephalogram. No important change in electroencephalographic activity occurred. This case provides evidence against the hypothesis that epileptic discharge is responsible for transient global amnesia.

Cole AJ, Gloor P, Kaplan R: Transient global amnesia: the electroencephalogram at onset. Ann Neurol 22:771-772, 1987

Transient memory loss may occur in association with temporal lobe seizures, stroke, migraine, temporal lobe encephalitis, drug intoxication, and hysteria [1]

From the Montreal Neurological Hospital and Institute, Montreal, Quebec, Canada.

Received Mar 26, 1987, and in revised form May 14 and June 4. Accepted for publication June 5, 1987.

Address correspondence to Dr. Cole, Johns Hopkins University School of Medicine, Department of Neuroscience, $725 \mathrm{~N}$ Wolfe St, Baltimore, MD 21205.
Transient global amnesia (TGA) is a specific stereotyped syndrome of altered behavior dominated by amnesia that occurs without other neurological symptoms or signs and resolves within hours [2].

Several etiological hypotheses have been advanced to explain TGA. Many reports have suggested a vascular mechanism [3]. Others have proposed an epileptic origin [4-7]. Some have suggested that ischemia may cause epileptic discharge, which in turn results in TGA $[8,9]$. Cardiac arrhythmia [10], concussion [11], anesthesia [12], possible benzodiazepine intoxication [13], and migraine $[14,15]$ have all been implicated in specific cases.

This report describes the fortuitous observation of a patient whose electroencephalogram (EEG) was being recorded at the time his attack began. No evidence of epileptic discharge either prior to, during, or after the attack was found.

\section{Case Report}

A 53-year-old right-handed man was referred for an EEG in the course of investigation of migraine. Midway through the EEG examination the technician spoke to the patient, who was able to carry on a normal conversation. The technician described the subsequent events: "When I entered the room to change to the last montage, the patient (who had acted perfectly normally until that time) suddenly said that he didn't know what he was doing there, or how he got there. He remembered the year he was born, but couldn't say how old he was. He remembered what he'd had for breakfast, but couldn't remember whether he'd driven here or come to town with a friend."

Examination by a neurologist demonstrated complete amnesia extending back to his arrival in the EEG laboratory. He was confused about how he arrived at the hospital. He asked repeatedly whether he had been to work that morning. $\mathrm{He}$ was oriented to person, place, and time, but was able to remember only 1 of 4 objects after 5 minutes. Digit span was 7 forward and backward. His recall of events over the preceding 3 days was patchy. His remote memory was intact, as was his calculation ability. The remainder of the neurological and systemic examination was normal. Investigations including electrocardiogram and cranial computed tomographic scanning were normal. Over the next 24 hours the patient completely recovered.

The EEG immediately prior to the onset of the attack and during the initial hour of the attack was normal. Background activity consisted of $9.5 \mathrm{~Hz}$ alpha rhythm dominant over posterior head regions, which was suppressed with eye opening (Figure, left panel). Hyperventilation resulted in generalized bursts of bilaterally synchronous slow waves with bifrontal predominance, which did not outlast the period of overbreathing. Immediately after the onset of TGA the background activity was unchanged, but superimposed were frequent eye blinks and some muscle artifact related to restlessness (see Figure, right panel). An EEG recorded 4 years earlier for evaluation of possible drop attacks was also normal. 